\title{
Gestão ambiental no setor público: percepção dos servidores da prefeitura municipal de São Gabriel (RS)
}

\author{
Environmental management in the public sector: perception of employees of the municipality of São Gabriel (RS) \\ Marianne Macedo Goulart Dambrós'; Ana Júlia Teixeira Senna²; Ricardo Ribeiro Alves ${ }^{3}$ \\ 1,3 Doutor(a), Universidade Federal do Pampa (UNIPAMPA), campus São Gabriel ,RS,Brasil \\ ${ }^{2}$ Gestora Ambiental - Universidade Federal do Pampa (UNIPAMPA), campus São Gabriel ,RS,Brasil
}

\section{Resumo}

As boas práticas de gestão ambiental, tão necessárias para a otimização dos recursos, diminuição de desperdícios e redução da poluição, não devem ser exercidas apenas pelas empresas. Os órgãos públicos, como as prefeituras municipais, também devem ter o compromisso com tais práticas, servindo como exemplo em toda a sociedade. Para tanto, esses órgãos devem ser capazes de capacitar e conscientizar seus funcionários, para que o exercício das práticas de gestão ambiental seja feito de forma contínua e não apenas em poucas ocasiões. O presente estudo foi realizado na prefeitura do município de São Gabriel (RS) e, para a obtenção dos dados, elaborou-se um questionário. Verificou-se que há falta de uniformidade com relação às práticas de gestão ambiental na prefeitura. Enquanto que funcionários de alguns setores declararam possuir lixeiras para coleta seletiva, outros setores não dispunham delas. Além disso, para alguns funcionários as práticas de gestão ambiental são importantes para a consecução de seu trabalho, ao passo que, para outros, é uma questão irrelevante. Pode-se concluir que em situações como essas se torna necessária a intervenção dos governantes para que haja, de fato, a implantação de projetos de gestão ambiental bem como de programas de educação ambiental e conscientização de seus funcionários. É possível que muitos destes servidores não adotem práticas de gestão ambiental pelo simples fato de não possuírem a instrução e conscientização necessária. Atuando dessa forma, os órgãos públicos teriam maior credibilidade no momento de cobrar atitudes ambientalmente responsáveis de empresas e indivíduos.

Palavras-chave: práticas ambientais, educação ambiental, conscientização.

\begin{abstract}
Good environmental management practices, as necessary for the optimization of resources, reduction of waste and pollution reduction, should not be exercised only by the companies. Public bodies such as municipalities, must also have a commitment to such practices, serving as an example to the whole society. Therefore, these bodies should be able to train and educate their employees, so that the performance of environmental management practices is done continuously and not only on a few occasions. This study was conducted in the Municipality of São Gabriel (RS), and to obtain the data, a questionnaire was drafted. It was found that there is a lack of uniformity with regard to environmental management practices at city hall. While some sectors of employees reported having to collection bins, other sectors did not have them. Additionally, for some employees the environmental management practices are important for the achievement of their work, while for others it is an irrelevant issue. It can be concluded that in such situations it becomes necessary the intervention of the government so that there is, in fact, the implementation of environmental management projects and programs for environmental education and awareness of its employees. It is possible that many of these servers do not adopt environmental management practices simply because they lack the necessary education and awareness. Acting this way, the public agencies would have greater credibility when you charge environmentally responsible businesses and individuals.
\end{abstract}

Keywords: environmental practices, environmental education, awareness. 


\section{INTRODUÇÃO}

Desde os primórdios da civilização o homem vem utilizando os recursos naturais para a sobrevivência. Contudo, nas últimas décadas, a exploração irracional dos desses recursos produziu efeitos devastadores ao meio ambiente. A falsa ideia de que os eles eram inesgotáveis "caiu por terra" e deu lugar à necessidade de maior otimização dos insumos retirados do meio ambiente e à maior conscientização de pessoas, empresas e governos.

Para uma parcela da sociedade, sobretudo o meio empresarial, o desenvolvimento sustentável era visto como uma limitação à prosperidade econômica. Esse aparente conflito somente foi desmistificado nos últimos anos ao se constatar que as boas práticas ambientais nas organizações, além de representar consciência ambiental, também podem significar redução de custos.

A responsabilidade com as questões ambientais, no entanto, é também dever de órgãos públicos, em níveis local, estadual e nacional. Pedrosa et al. (2007) destacaram que os municípios precisam se mostrar capazes de enfrentar esse novo desafio, ou seja, gerar desenvolvimento sem destruir o meio natural. Para os autores, as prefeituras que agem dessa forma podem servir de modelo para os demais municípios brasileiros, a fim de influenciá-los e estimulá-los a tomar atitudes de preservação ambiental e de enfatizar as responsabilidades dos governos locais, que são entre outras, de acordo com a legislação brasileira: proteger o meio ambiente, combater a poluição e preservar as florestas, fauna e flora.

Sendo assim, tornam-se necessários estudos que apresentem o compromisso de órgãos públicos, em particular as prefeituras, com as boas práticas ambientais. O presente trabalho teve por objetivo analisar a percepção dos servidores da Prefeitura Municipal de São Gabriel, localizada no interior do Rio Grande do Sul, com relação às práticas de gestão ambiental.

\section{REVISÃO DE LITERATURA}

\section{I ORIGEM DO DESENVOLVIMENTO SUSTENTÁVEL}

A partir da década de 1970 intensificaram as mobilizações em todo mundo a respeito das questões ambientais devido a diversos tipos fatores como desmatamentos, desertificação, diminuição da camada de ozônio etc. Surgiram, a partir de então, várias conferências internacionais para se discutir os problemas relacionados às mudanças no meio ambiente.

A primeira Conferência das Nações Unidas sobre o Meio Ambiente Humano, ocorrida em 1972, mais conhecida como Conferência de Estocolmo, foi convocada pela Assembleia das Nações Unidas. Um dos resultados positivos dessa primeira conferência foi a entrada definitiva da questão ambiental na agenda internacional multilateral. Além disso, outros aspectos também foram importantes como a criação do Programa das Nações Unidas para o Meio Ambiente (PNUMA), o incentivo à criação de órgãos específicos internos dos países para tratar do tema e o fortalecimento das organizações não governamentais e da participação civil.

A partir dessa primeira conferência novos termos surgem relacionados à questão ambiental como, por exemplo, desenvolvimento sustentável e sustentabilidade. Para Cavalcanti et al. (1994) apud Gonçalves (2005), sustentabilidade significa a possibilidade de se obterem continuamente condições iguais ou superiores de vida para um grupo de pessoas e seus sucessores em dado ecossistema. Tal conceito equivale à ideia de manutenção do sistema de suporte da vida em uma perspectiva de longo prazo.

Com o objetivo de ampliar o conhecimento global em torno do tema ambiental e os problemas relacionados ao desenvolvimento, em 1987 foi apresentado, pela Comissão Mundial sobre Meio Ambiente e Desenvolvimento, o Relatório Brundtland. O documento, que possui base científica, promoveu o enriquecimento do debate acerca do tema e teve ampla divulgação. Um de seus principais sucessos foi a criação do conceito de desenvolvimento sustentável que, segundo Peixoto et al. (2005), pode ser definido como aquele onde os indivíduos conservam os bens hoje existentes para que não haja comprometimento das necessidades das gerações futuras. Ao se pensar em desenvolvimento sustentável, este deve estar associado à qualidade de vida. Entretanto, não se pode considerar qualidade de vida como a possibilidade de consumir e adquirir um maior número de produtos. A prática deste pensamento gera cada vez mais resíduos, que se não forem reutilizados ou reciclados causam poluição no ar, nos solos e nos rios ou saturam os aterros sanitários.

A conferência de 1992 realizada no Rio de Janeiro, também conhecida como Rio 92, foi con- 
vocada dois anos após a divulgação do Relatório Brundtland e contou com a participação de 172 delegações e 108 Chefes de Estado ou de Governo. A Rio 92 foi vista por Maurice Strong, Secretário Geral da Conferência, como um momento histórico para a humanidade já que mostrou a importância adquirida pela questão do meio ambiente na agenda internacional.

\subsection{GeSTÃo AMBIENTAL NAS EMPRESAS}

A partir da concepção de desenvolvimento sustentável, surgiram políticas, programas e práticas administrativas e operacionais para a proteção do meio ambiente, além de segurança e saúde das pessoas.

A área de meio ambiente nas empresas foi ganhando destaque em níveis cada vez mais altos na hierarquia, em postos como gerente de meio ambiente, supervisor ambiental, gerente de práticas de gestão ambiental, entre outros.

Introduzir a gestão ambiental nos patamares superiores das organizações, notadamente naqueles com maior poder de decisão, é importante para promover e fortalecer mudanças de atitudes nas pessoas e repensar processos nas organizações e na sociedade como um todo. Passos (2010) destacou que a gestão ambiental exige a integração de sistemas e programas organizacionais que possam trazer uma redução e controle na geração de resíduos, cumprindo com as leis ambientais, avaliando e monitorando os processos ambientais, desenvolvendo tecnologias alternativas apropriadas para minimizar ou excluir riscos ambientais e reduzir gastos, antecipando os problemas relacionados que possam causar prejuízos e multa, além de danos à imagem da organização onde será desenvolvido o sistema. Assim, a prática de gestão ambiental contribui para o avanço e o desenvolvimento, minimizando os impactos ao meio ambiente.

De acordo com Seiffert (2009), gestão ambiental não é um conceito novo nem uma necessidade nova, mas algo que foi amadurecendo ao longo dos anos, a partir das contribuições de várias áreas do conhecimento, mas particularmente das engenharias, ciências biológicas, administração, geologia e geografia.

Os programas de gestão ambiental nas organizações vão ao encontro da responsabilidade social preconizada em suas políticas e missões. Segundo Tinoco e Kraemer (2011), a responsabilidade social é convergente com estratégias de sustentabilidade de longo prazo, inclui a necessária preocupação dos efeitos das atividades desenvolvidas no contexto da comunidade em que se inserem as empresas.

\subsection{GeStÃo AMBIENTAL NOS ÓRGÃOS PÚblicos}

O Poder Público pode ser definido como o detentor de poderes e obrigações estabelecidos na legislação, que lhe permitem promover desde o ordenamento e controle do uso dos recursos ambientais (incluindo a criação de incentivos fiscais na área ambiental) até a reparação e a prisão de indivíduos pelo dano ambiental. Neste sentido, o Poder Público estabelece padrões de qualidade ambiental, avalia impactos ambientais, licencia e revisa atividades efetiva e potencialmente poluidoras, disciplina a ocupação do território e o uso de recursos naturais, cria e gerencia áreas protegidas, obriga a recuperação do dano ambiental pelo agente causador, promove o monitoramento, a fiscalização, a pesquisa, a educação ambiental e outras ações necessárias ao cumprimento da sua função mediadora (QUINTAS, 2002).

Tomando por base a definição anterior, nota-se que cabe ao Poder Público, por meio de suas diferentes esferas, intervir neste processo, de modo a evitar que os interesses de determinados atores sociais (madeireiros, empresários de construção civil, industriais, agricultores, moradores etc.) provoquem alterações no meio ambiente que ponham em risco a qualidade de vida da população afetada (DA SILVA, 2008).

Nesse sentido, Seiffert (2009) destacou que a gestão ambiental na esfera pública é dependente da implementação pelo governo de sua política ambiental, mediante a definição de estratégias, ações, investimentos e providências institucionais e jurídicas, com a finalidade de garantir a qualidade do meio ambiente, a conservação da biodiversidade e o desenvolvimento sustentável.

No âmbito das prefeituras municipais há demanda por estratégias voltadas ao equacionamento do lixo urbano, que, normalmente, é depositado a céu aberto com a decorrente atração de uma população marginalizada, que passa a sobreviver em função dessa situação. Como a capacidade dos lixões e aterros sanitários (incineração a céu aberto e sem controle de sua queima) fica saturada rapidamente, principalmente nas grandes cidades, abrem-se possibilidades para o desenvolvimento de projetos sociais e ambientais no contexto dos governos municipais (TACHIZAWA, 2005). 


\section{MATERIAL E MÉTODOS}

O presente estudo foi realizado na prefeitura do município de São Gabriel, no Rio Grande do Sul, em sete secretarias. Para a obtenção dos dados, elaborou-se um questionário com quatorze questões. De acordo com Malhota (2001), o questionário é uma técnica estruturada para a coleta de dados, que consiste em uma série de perguntas que um entrevistado deve responder. Para Michel (2009), o questionário é considerado um instrumento de valor significativo de coleta de dados, mais utilizado para coletar dados quantitativos e informativos. Além disso, segundo a autora, eventualmente se colocam questões abertas para medir clima, opiniões, expectativas. Por fim, Gil (1987), destacou que o questionário é uma técnica de investigação composta por um número mais ou menos elevado de questões apresentadas por escrito às pessoas, tendo por objetivo o conhecimento de opiniões, crenças, sentimentos, interesses, expectativas, situações vivenciadas etc. Ainda, segundo o autor, a aplicação do questionário possibilita atingir grande número de pessoas, mesmo que estejam dispersas. Também implica menores gastos com pessoal, posto que o questionário não exige o treinamento dos pesquisadores, mantém o anonimato das respostas, e as pessoas se sentem mais à vontade respondendo o questionário, ao invés de participar de uma entrevista.

O questionário utilizado nesta pesquisa encontra-se após o final do presente artigo, na seção Apêndice. Foi aplicado um total de 57 questionários nas sete secretarias da prefeitura municipal e obteve-se um total de 35 questionários respondidos, conforme apresentado na Tabela 1.

Tabela 1 - Número de questionários aplicados e respondidos em cada secretaria.

\begin{tabular}{|c|c|c|c|}
\hline 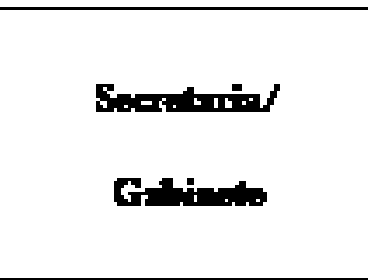 & 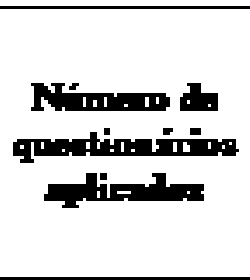 & 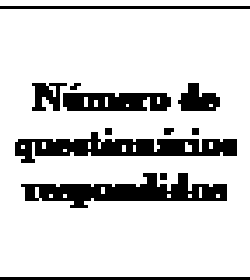 & 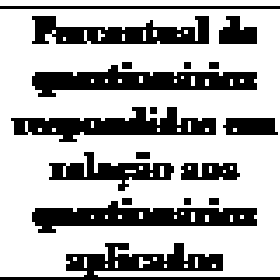 \\
\hline 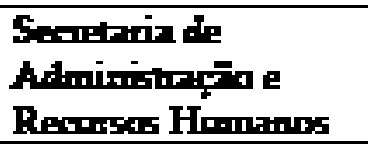 & 12 & 6 & 5ณ, \\
\hline $\begin{array}{l}\text { Secutrian Gerl de } \\
\text { Gavema }\end{array}$ & 4 & $\mathbf{2}$ & $5 \mu 0 x$ \\
\hline $\begin{array}{l}\text { Secotarix dix } \\
\text { Fanendx }\end{array}$ & 7 & 4 & $57,1 \%$ \\
\hline 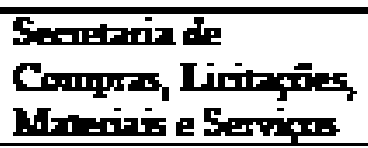 & 13 & 9 & 67,24 \\
\hline 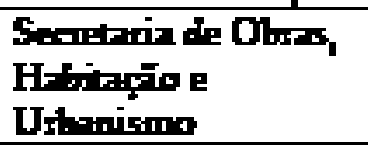 & 11 & 11 & $101 \%$ \\
\hline Gabindedo Prefito & 3 & $\mathbf{0}$ & $\mathbf{O F}$ \\
\hline $\begin{array}{l}\text { Secretria de } \\
\text { Plangamental e } \\
\text { Phoides }\end{array}$ & 7 & 3 & $428 x$ \\
\hline Tot' & 57 & $\mathbf{3 5}$ & 61,26 \\
\hline
\end{tabular}

Fonte: Dados dos autores.

À exceção do Gabinete do Prefeito no qual não se obtiveram respostas, em todas as secretarias a taxa de retorno dos questionários aplicados foi maior que $40 \%$. Além disso, no geral a taxa foi de 61,4\%. Podem-se considerar satisfatórios os índices de retorno dos questionários desta pesquisa já que, de acordo com Michel (2009), o alcance médio de respostas geralmente fica em torno de 25\%, 
portanto, os obtidos no presente estudo, são bem superiores.

\section{RESULTADOS E DISCUSSÕES}

\section{I ASPECTOS GERAIS SOBRE O CARGO DOS FUNCIONÁRIOS}

Do total de questionários o maior percentual de respostas obtido foi na Secretaria de Obras, Habitação e Urbanismo, seguido pela Secretaria de Compras, Licitações, Materiais e Serviços (Figura 1). De acordo com PMSG (2012), essa secretaria é responsável pelas obras públicas e urbanismo, elaboração de planos urbanísticos, sinalização de ruas e logradouros públicos, fiscalização de edificações e loteamentos, bem como obras públicas não municipais e parecer sobre o seu licenciamento, demolição e outras. Sua atuação, portanto, é decisiva na autorização de obras na cidade e, também, no acompanhamento das externalidades advindas delas e que possam causar impactos negativos ao meio ambiente

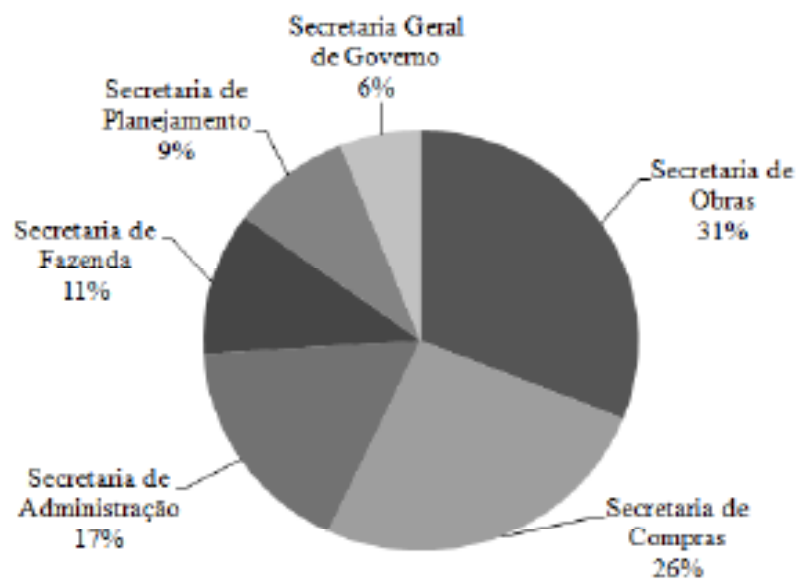

Figura 1 - Secretarias da prefeitura as quais pertencem os funcionários da prefeitura que responderam à pesquisa. Fonte: Dados dos autores.

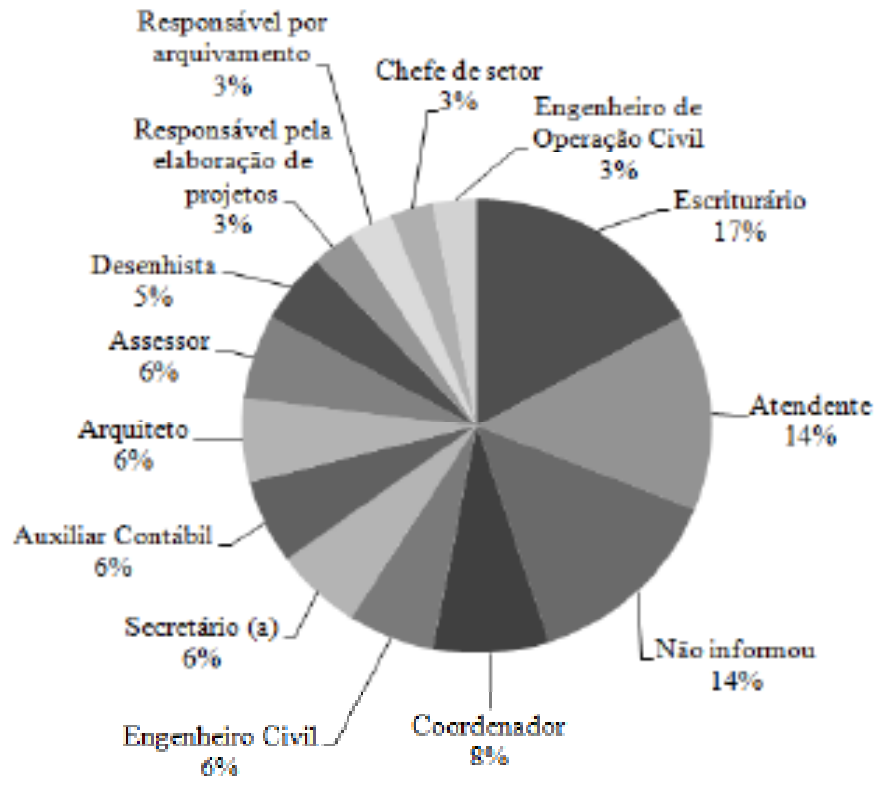

Figura 2 - Função exercida pelos funcionários da prefeitura que responderam à pesquisa.

Fonte: Dados dos autores. 
Já a Secretaria de Compras, Licitações, Materiais e Serviços é o órgão encarregado de exercer as atividades ligadas no que concerne a material, compras, oficinas, abastecimentos e conservação de veículos e provisionamento geral para o exercício da administração pública (PMSG, 2012). Um dos aspectos em que essa secretaria pode contribuir em relação à questão ambiental é verificar a real necessidade dos materiais solicitados e ponderar sobre a possibilidade de redução de seu consumo.

As funções exercidas na prefeitura pelos funcionários que responderam à pesquisa são as mais diversas conforme apresentado na Figura 2, destacando-se os cargos de escriturário e atendente.

\subsection{AsPeCtos GeraIS SOBRE MEIO AMBIENTE}

O agravamento da problemática ambiental, evidenciada pela poluição, desmatamentos, enchentes e secas, dentre outros, atingem de forma desigual a população do planeta. Algumas pessoas sofrem mais diretamente os efeitos provocados pelas mudanças climáticas enquanto que, para outras, esses efeitos são indiferentes. Para a maioria dos funcionários da prefeitura essas questões ambientais afetam o seu dia a dia (Figura 3 ).

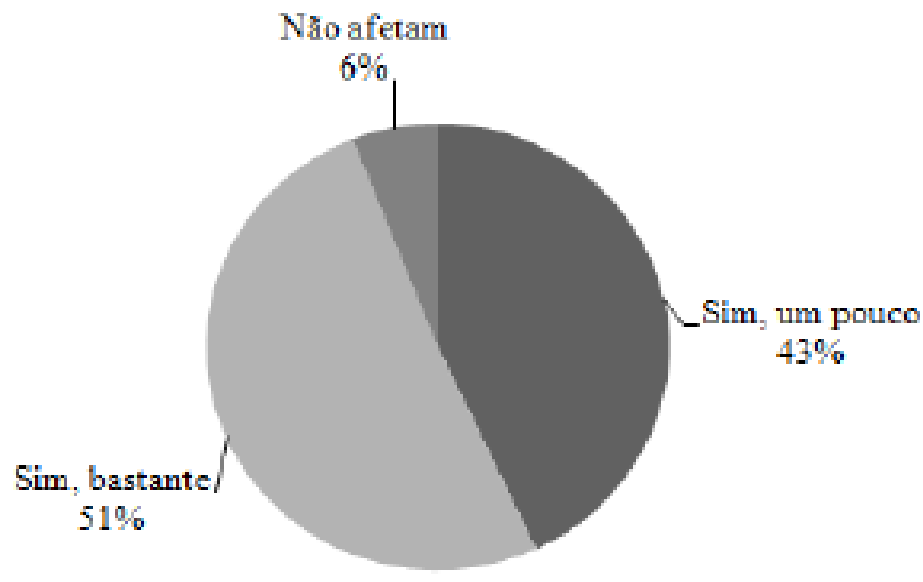

Figura 3 - Influência das questões ambientais no dia a dia dos funcionários da prefeitura.

Fonte: Dados dos autores.

Para algumas pessoas as discussões em torno da problemática ambiental, de assuntos como poluição, desmatamento etc., embora sejam importantes para elas, não fazem parte de suas preocupações mais imediatas. Essas pessoas não se sentem corresponsáveis pela degradação do meio ambiente e nem se consideram parte da solução do problema. A Figura 4 apresenta a opinião dos funcionários da prefeitura acerca dessa questão.

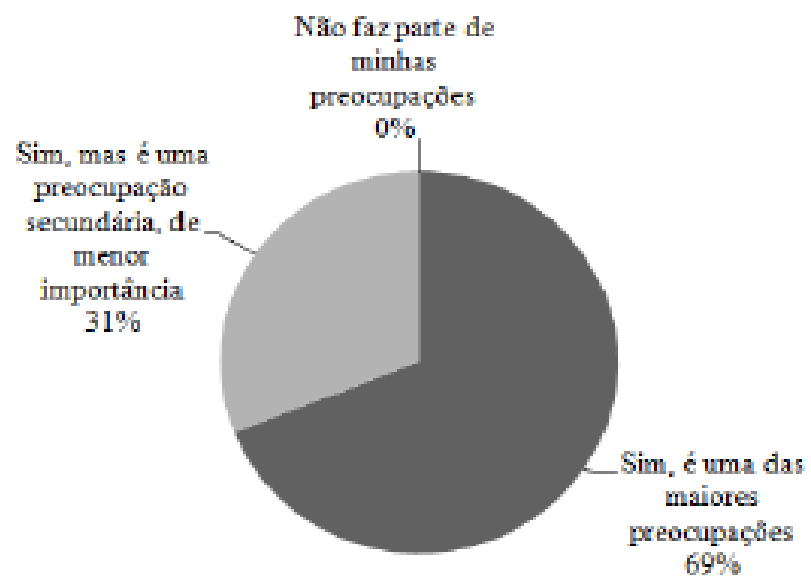

Figura 4 - As questões ambientais como fator de preocupação para os funcionários da prefeitura.

Fonte: Dados dos autores. 
Embora os problemas relacionados com o agravamento da degradação do meio ambiente tenham crescido progressivamente nas últimas décadas, as pessoas podem tomar parte na solução do problema. Uma das formas para se atingir esse propósito são as práticas de gestão ambiental. Por meio dessas práticas as pessoas podem contribuir em diversos aspectos tais como economia de energia, economia de água, consumo de produtos que sejam ecologicamente sustentáveis, utilização de coleta seletiva ao invés da coleta tradicional que prejudica a reciclagem dos materiais, maior utilização de transporte coletivo em relação ao transporte individual, escolha de produtos com embalagens mais compactas, dentre outros.

Enquanto alguns funcionários da prefeitura sabem reconhecer o que são práticas de gestão ambiental, verificou-se que outros não sabem o que são, conforme apresentado na Figura 5.

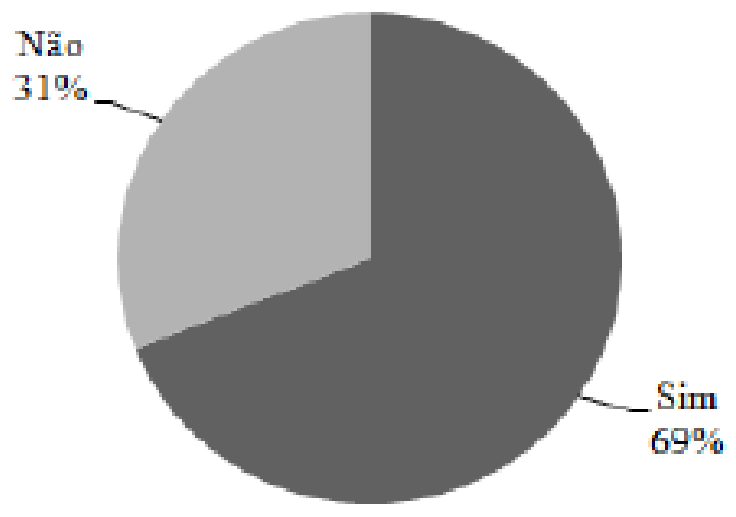

Figura 5 - Conhecimento das práticas de gestão ambiental pelos funcionários da prefeitura.

Fonte: Dados dos autores.

O ideal é que o trabalho seja uma extensão do que se faz em casa. Sendo assim, para que as práticas de gestão ambiental sejam eficazes torna-se interessante que elas façam parte do dia a dia dos trabalhadores e que, primeiramente, sejam aplicadas em suas próprias residências (Figura 6).

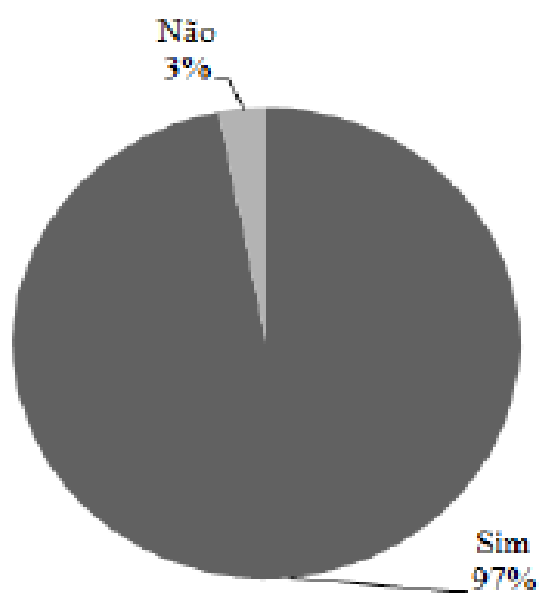

Figura 6 - Realização de práticas de gestão ambiental nas residências dos funcionários da prefeitura.

Fonte: Dados dos autores.

De acordo com a Figura 6 verifica-se que, dos funcionários que sabem o que são práticas de gestão ambiental, a maioria deles realiza alguma atividade ligada à questão ambiental em suas residências. 
Para compreender quais seriam as práticas ambientais realizadas por eles em suas casas pediu-se para citar as principais ações (Figura 7).

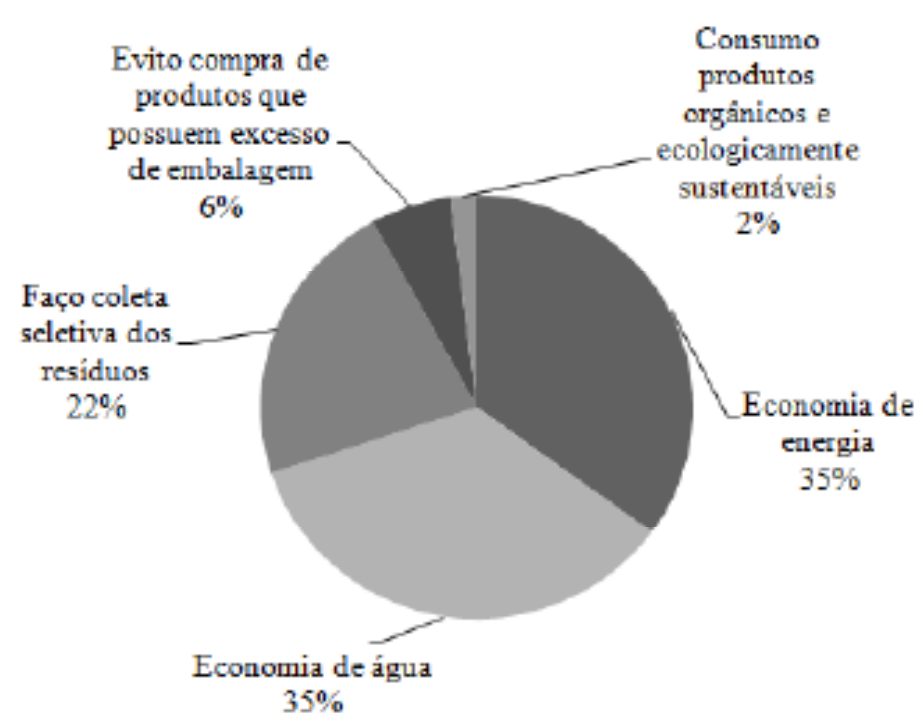

Figura 7 - Principais práticas de gestão ambiental realizadas pelos funcionários da prefeitura fora do ambiente de trabalho.

Fonte: Dados dos autores.

Pelo apresentado na Figura 7, as principais práticas de gestão ambiental realizadas pelos funcionários da prefeitura fora de seu ambiente de trabalho estão mais relacionadas ao aspecto econômico, como no caso das economias de água e de energia elétrica. Tais resultados são compreensíveis visto que as pessoas têm maior motivação com relação ao meio ambiente quando a prática vem acompanhada de ganhos econômicos. Um exemplo claro é no momento da escolha de um eletrodoméstico quando, ao se optar por um modelo classificado com menor consumo (tipo "A"), se consome menos energia (aspecto ambiental) e ao mesmo tempo se paga menos energia (aspecto econômico). Dessa forma, o aspecto econômico é um importante motivador para o consumidor.

\subsection{AsPeCtOS SOBRE MEIO AMBIENTE NA PREFEITURA}

Após o levantamento do conhecimento dos funcionários acerca do agravamento das questões ambientais e também das práticas de gestão ambiental em suas residências, tornou-se importante avaliar a temática "meio ambiente" em seu local de trabalho, ou seja, na prefeitura (Figura 8).

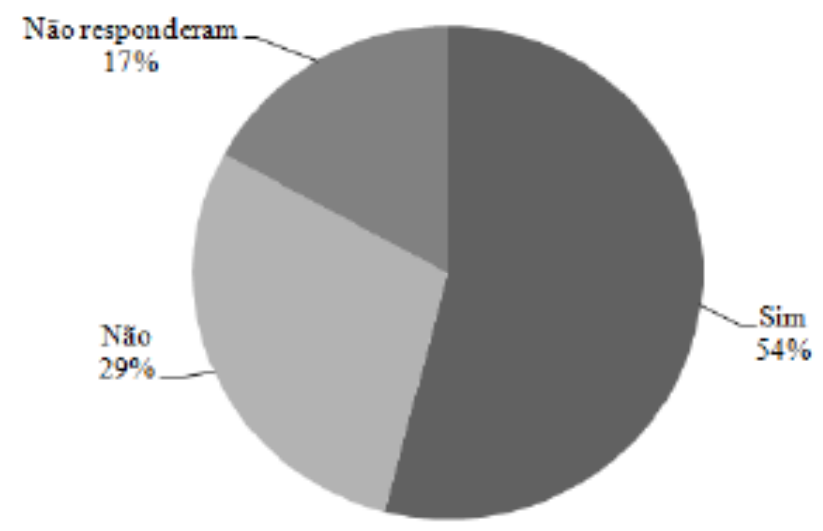

Figura 8 - Existência de práticas de gestão ambiental na prefeitura segundo seus funcionários.

Fonte: Dados dos autores. 
De acordo com os resultados apresentados na Figura 8, a maior parte dos funcionários relatou que existem práticas de gestão ambiental na prefeitura enquanto que, um percentual considerável (29\%), afirma que não existem tais práticas. Estes últimos podem estar desinformados sobre as práticas de gestão ambiental (ou não conhecê-las), uma vez que os respondentes que afirmaram existir tais práticas descrevem algumas:

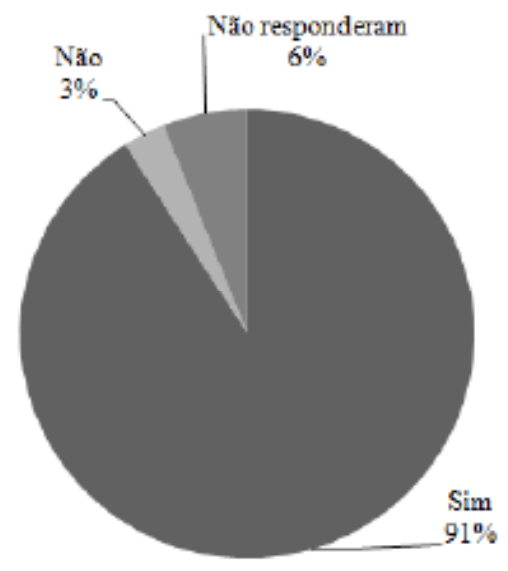

Figura 9 - Conhecimento dos funcionários da prefeitura acerca do funcionamento da coleta seletiva.

Fonte: Dados dos autores

- "Existe coleta seletiva no departamento embora com pouca resposta dos funcionários, talvez evidenciando a necessidade de maior conscientização deles".

- "Há um projeto na secretaria visando a coleta seletiva de resíduos e a economia de energia. Os funcionários evitam ligar o ar condicionado, quando desnecessário".

- "Há apoio à coleta seletiva e aos trabalhadores da reciclagem".

Como alguns servidores descreveram a coleta seletiva de resíduos como uma importante prática de gestão ambiental, se tornou importante saber se eles, de fato, sabiam como funcionava essa prática (Figura 9). Apesar de os funcionários terem ciência a respeito do funcionamento da coleta seletiva, a maioria deles relatou que existia tal tipo de coleta em seu setor (Figura 10). Embora esse resultado pareça contradizer os obtidos na Figura 8, deve-se atentar que na ocasião a pergunta se referia à prefeitura como um todo, sendo que agora, na Figura 10, ela é específica do setor da qual o respondente faz parte.

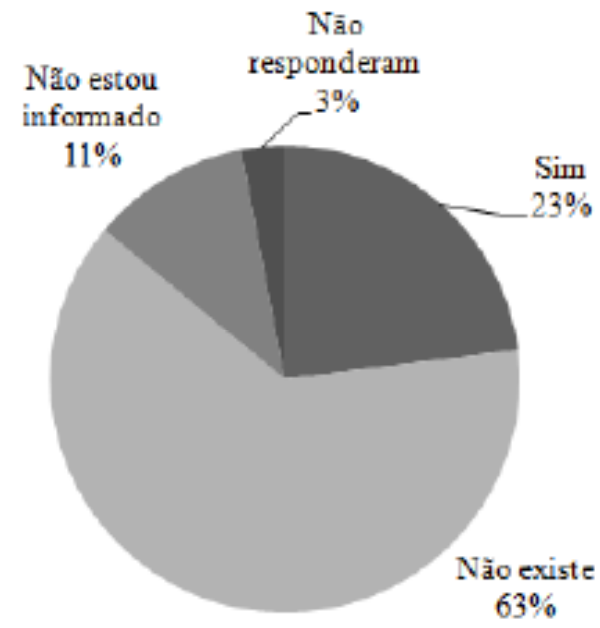

Figura 10 - Existência de um programa de coleta seletiva nos setores de trabalho dos funcionários que responderam à pesquisa. Fonte: Dados dos autores. 
Para os funcionários que afirmaram existir coleta seletiva em seu setor, procurou-se saber qual era a atitude deles com relação ao uso efetivo dessa lixeira (Figura 11).

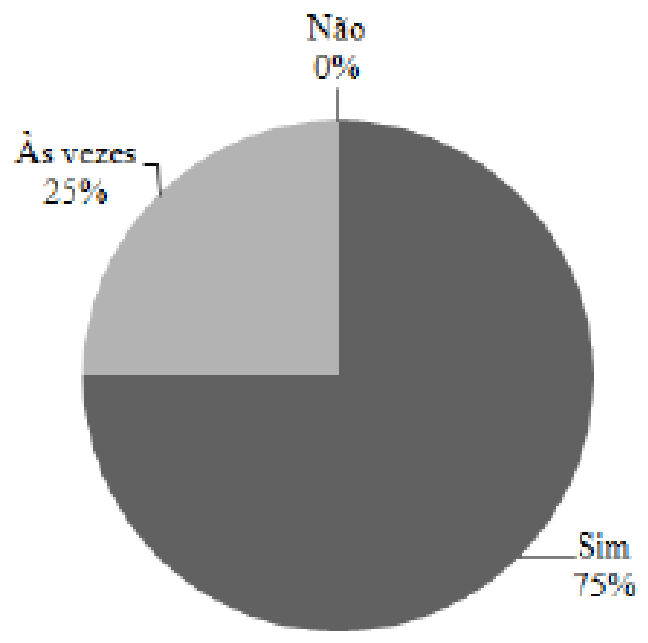

Figura 11 - Atitude dos funcionários quanto a jogar lixo e demais resíduos na lixeira da coleta seletiva.

Fonte: Dados dos autores.

Verificou-se, então, que a maioria dos respondentes utilizava com frequência a lixeira da coleta seletiva. No entanto, $1 / 4$ deles relatou que "às vezes" jogava o resíduo correto na lixeira correspondente. Alguns relataram que não o faziam com frequência simplesmente por que "esqueciam". Para eficácia de um programa de gestão ambiental é necessário investigar quais razões levam esses funcionários a não utilizar com frequência a coleta seletiva o que, provavelmente, apontará para a necessidade de maior treinamento e conscientização a respeito das boas práticas de gestão ambiental.

Para os funcionários que relataram possuir lixeira de coleta seletiva em seu setor, perguntou-se a respeito das principais ações praticadas em resíduos destinados às lixeiras (Figura 12).

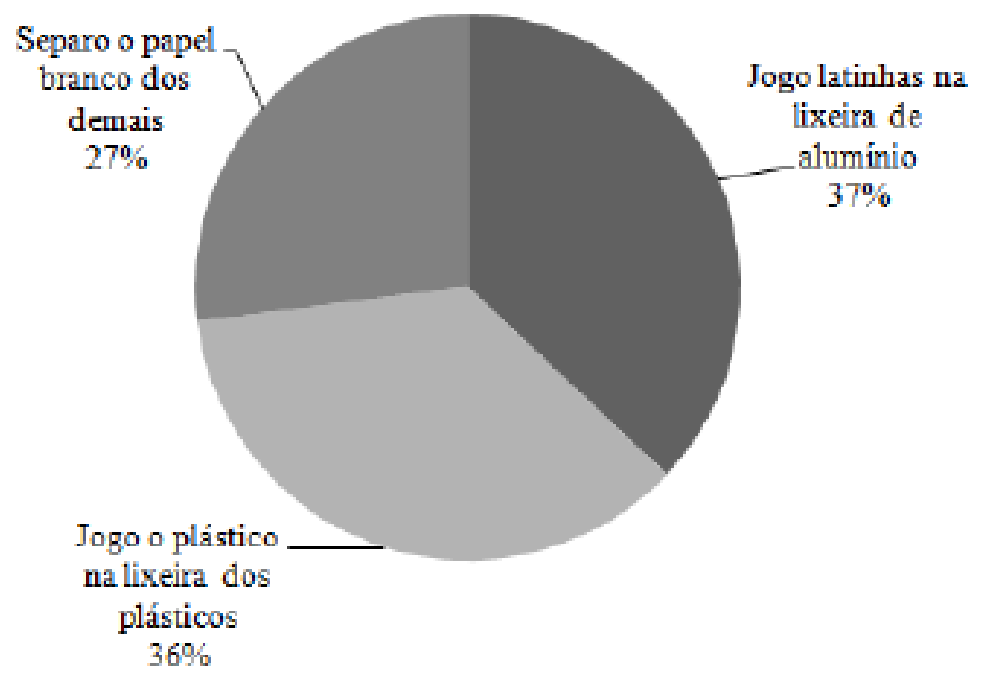

Figura 12 - Práticas realizadas pelos funcionários com relação à coleta seletiva na prefeitura.

Fonte: Dados dos autores.

De acordo com os resultados apresentados na Figura 12, pode-se notar que os principais resíduos jogados nas lixeiras são as latas de alumínio, o plástico e o papel. 


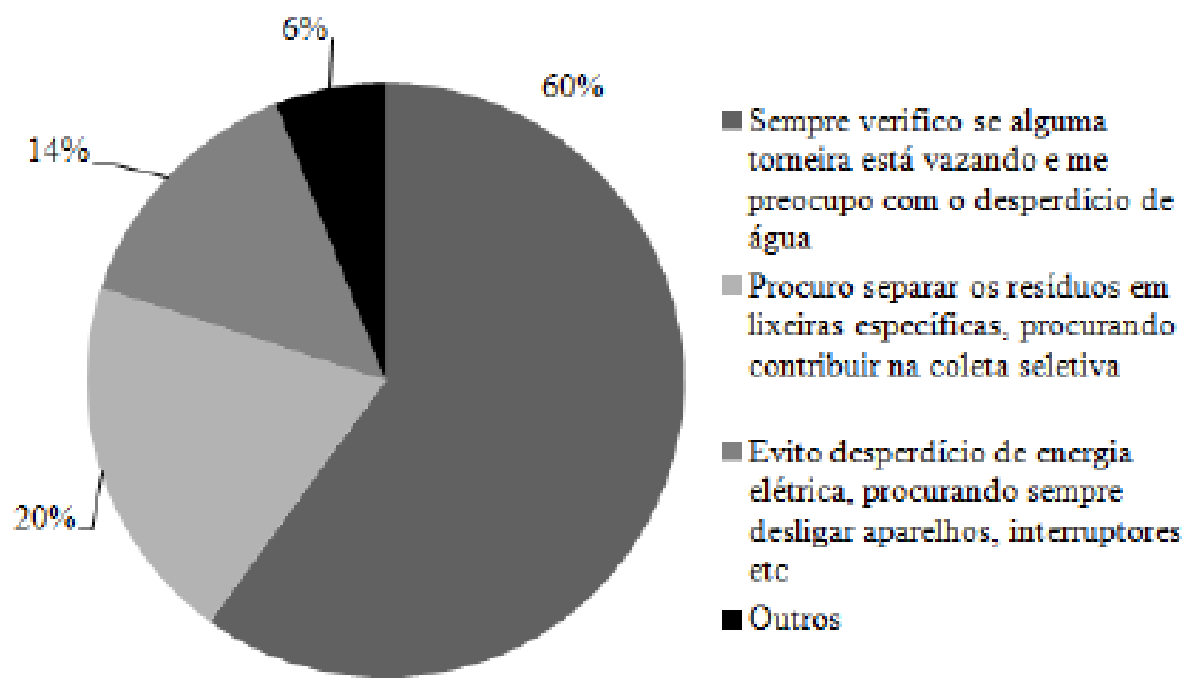

Figura 13 - Práticas realizadas pelos funcionários na prefeitura para contribuir na economia e na preservação do meio ambiente. Fonte: Dados dos autores.

Com relação às práticas específicas de gestão ambiental exercidas pelos funcionários na prefeitura, verificou-se que a preocupação é o desperdício de água no órgão público (Figura 13).

Idealmente as práticas de gestão ambiental deveriam ser praticadas por empresas, indivíduos e órgãos governamentais, de forma voluntária, denotando seus compromisso e consciência ambiental. Como, via de regra, é o que não acontece, são necessárias legislações que venham a impor a conduta correta dos atores sociais citados. Duas das leis surgidas para esse fim são o Decreto 5.940 (BRASIL, 2011a) e a Política Nacional de Resíduos Sólidos (BRASIL, 2011b). Com base nessa discussão, os respondentes foram inquiridos a respeito da importância de implementação de leis aplicáveis ao tratamento de resíduos descartados para as prefeituras (Figura 14).

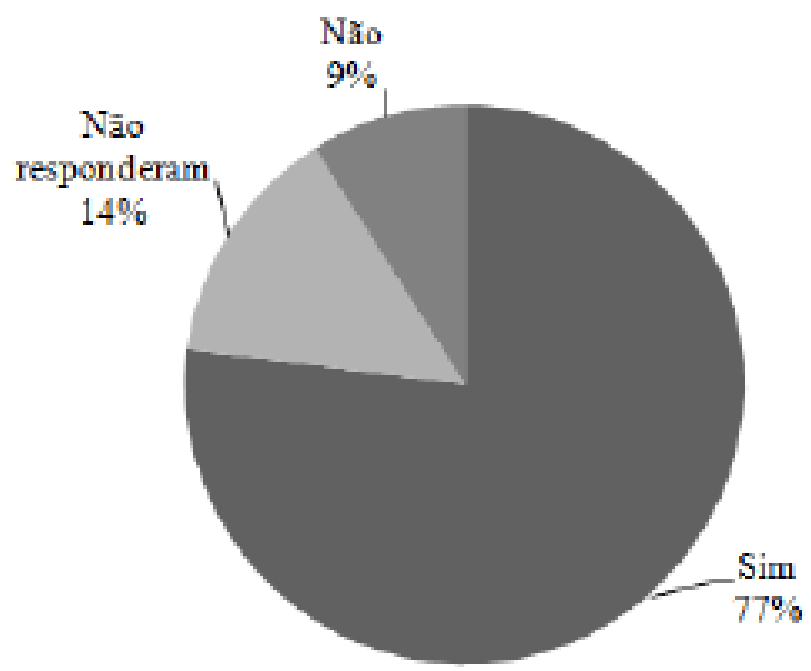

Figura 14 - Importância da implementação de leis aplicáveis ao tratamento de resíduos descartados para as prefeituras. Fonte: Dados dos autores.

A maior parte dos funcionários que responderam à pesquisa destacou a importância de leis para o efetivo cumprimento de práticas de gestão ambiental na prefeitura. Para esses funcionários a implementação de leis desse tipo favoreceriam um maior respeito ao meio ambiente por todos os servidores favorecendo, também, uma maior conscientização (Figura 15). 


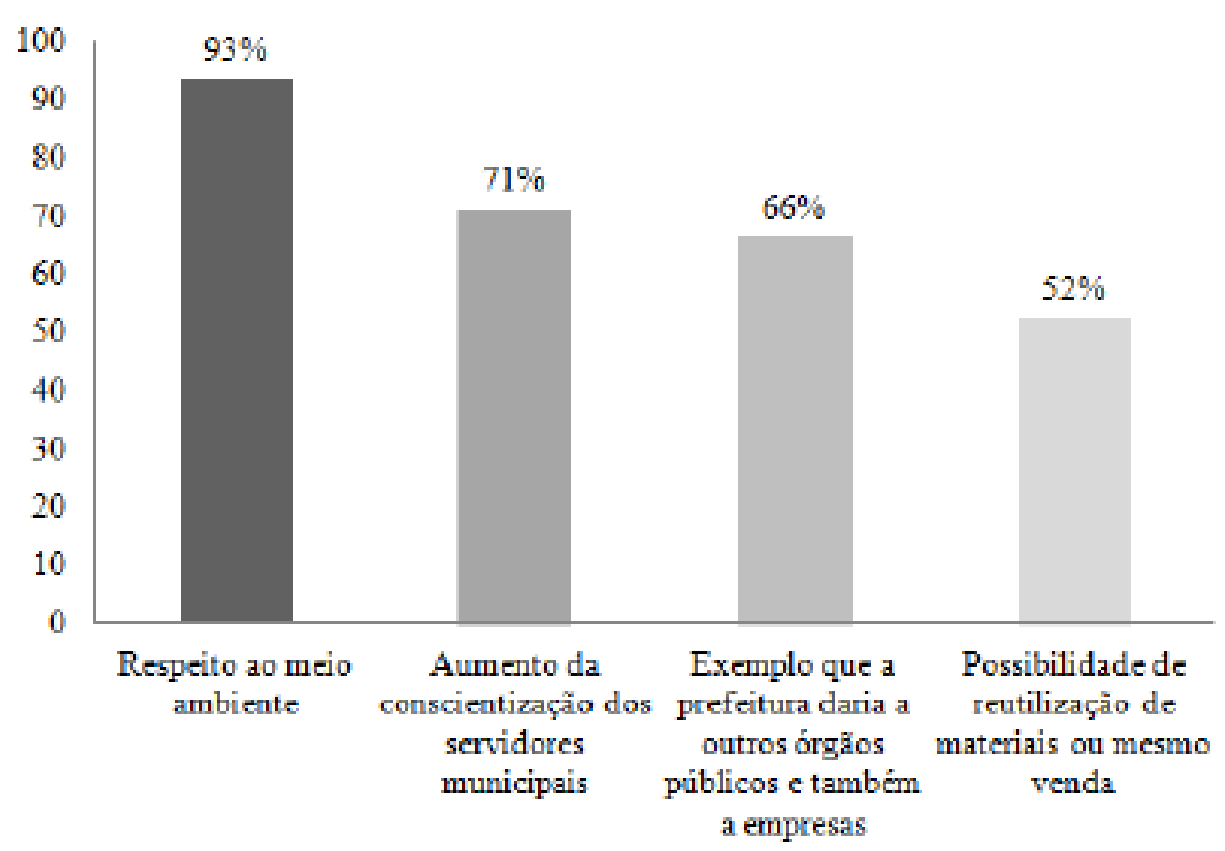

Figura 15 - Vantagens da existência de uma lei municipal que instituísse a separação e reciclagem de materiais segundo os funcionários da prefeitura.

Fonte: Dados dos autores.

Em relação ao interesse pelas práticas de gestão ambiental, a maioria dos servidores acreditam que a prefeitura demonstra interesse nessas questões, mas que esse interesse poderia ser maior. Para os que não acreditam no interesse do órgão público, as principais justificativas foram:

"Percebo que, para a grande maioria, não há interesse de adotar práticas de gestão ambiental." "Não há uma secretaria do meio ambiente, o que já demonstra a falta de interesse."

"Não há coleta seletiva, existem problemas de conscientização da população, falta de apoio aos recicladores (catadores)".

Dentre as sugestões apresentadas para melhoria, em termos ambientais, na prefeitura, destacam-se:

- Adoção de práticas de educação ambiental para cada setor ou secretaria do órgão público.

- Substituição de lâmpadas e torneiras por similares que possuem sensor de funcionamento, contribuindo para diminuir o consumo de energia elétrica e água.

- Instituição de uma disciplina nas escolas municipais, com o apoio da secretaria de educação, conscientizando e esclarecendo as crianças a respeito das práticas de gestão ambiental.

\section{CONCLUSÕES}

Muito se diz sobre a responsabilidade que as empresas e os indivíduos devem ter com relação às práticas de gestão ambiental. Todavia, tal responsabilidade deve ser estendida aos órgãos públicos, com as prefeituras, por exemplo.

No estudo realizado fica caracterizada a falta de uniformidade com relação às práticas de gestão ambiental na prefeitura. Enquanto que funcionários de alguns setores declararam possuir lixeiras para coleta seletiva, outros setores não dispunham delas. Além disso, verifica-se que para alguns funcionários as práticas de gestão ambiental são importantes para a consecução de seu trabalho, ao passo que, para outros, é uma questão irrelevante.

Em uma situação como essa torna-se necessária a intervenção dos governantes para que haja, 
de fato, a implantação de projetos de gestão ambiental bem como de programas de educação ambiental e conscientização de seus funcionários. É possível que muitos destes servidores não adotem práticas de gestão ambiental pelo simples fato de não possuírem a instrução e conscientização necessária.

Atuando dessa forma, os órgãos públicos, como as prefeituras, dariam exemplo para a sociedade e teriam maior credibilidade no momento de cobrar atitudes ambientalmente responsáveis de empresas e indivíduos.

\section{REFERÊNCIAS}

BRASIL. Decreto n 5.940, de 25 de outubro de 2006. Separação de resíduos sólidos. Licitações sustentáveis.

Disponível em: <http://www.licitacoessustentaveis.com/2009/08/decreto-n-594006-separacao-de-residuos. html>. Acesso em: $08 \mathrm{dez} 2011 \mathrm{a}$.

BRASIL. Política Nacional de resíduos sólidos. Lei no 12.305, de 2 de agosto de 2010 artigo 10. Disponível em: <http://www.abinee.org.br/informac/arquivos/lei12305.pdf>. Acesso em: $01 \mathrm{dez} 2011 \mathrm{~b}$.

CAVALCANTI, C.; FURTADO, A.; STAHEL, A.; RIBEIRO,A.; MENDES, A.; SEKIGUCHI, C.; MAIMON, D.; POSEY, D.; PIRES, E.; BRÜSEKE, F.; ROHDE, G.; MAMMANA, G.; LEIS, H.; ACSELRAD, H.; MEDEIROS, J.; D'AMATO, J. L.; LEONARDI, M. L.; TOLMASQUIM, M.; FILHO, O. S.; STROH, P.; FREIRE, P.; MAY, P.; DINIZ, P.; MAGALHÃES, A. R. Desenvolvimento e natureza: estudos para uma sociedade sustentável. Recife: INPSO/FUNDAJ, Instituto de Pesquisas Sociais, Fundacao Joaquim Nabuco, Ministério da Educação. 1994.

DA SILVA, B. M. S. Proposta de implantação do projeto de coleta seletiva no Departamento da Polícia Federal de Ilhéus, Bahia. Relatório de estágio supervisionado (Graduação em Ciências Administrativas e Contábeis) - Universidade Estadual de Santa Cruz (UESC). Ilhéus, BA. 2008.

GIL, A. C. Métodos e técnicas de pesquisa social. São Paulo: Atlas, 1987.

GONÇALVES, D. B. Desenvolvimento sustentável: o desafio da presente geração. Revista Espaço Acadêmico, ano V, n.51, ago 2005.

MALHOTRA, N. K. Pesquisa de Marketing: uma orientação aplicada. Porto Alegre: Bookman, 2001.

MICHEL, M. H. Metodologia e pesquisa científica em ciências sociais. 2 ed. São Paulo: Atlas, 2009. 204p.

PASSOS, G. Licenciamento Ambiental: regularização de um balneário às margens do rio Vacacaí. Relatório de estágio supervisionado (Graduação em Gestão Ambiental). Universidade Federal do Pampa, 2010.

PEDROSA, I. V.; KAKUTA, A. E; LEÃO, C. Z. C.; DA SILVA, E. M. Os municípios e o meio ambiente em Pernambuco. Relatório de pesquisa - 2006-2007. Recife: Faculdade de Ciências da Administração de Pernambuco (FCAP), Núcleo de Pesquisas em Economia do Setor Público. 2007.

PEIXOTO, K.; CAMPOS, V. B. G.; D’AGOSTO, M. A. A coleta seletiva e a redução dos resíduos sólidos. Rio de Janeiro: Instituto Militar de Engenharia. 2005

PMSG - PREFEITURA MUNICIPAL DE SÃO GABRIEL. Disponível em: < http://www.saogabriel.rs.gov. br>. Acesso em: 12 set 2012.

QUINTAS, J. S. Introdução à Gestão Ambiental Pública. Brasília: Edições IBAMA, 2002.

SEIFFERT, M. E. B. Gestão ambiental: instrumentos, esferas de ação e educação ambiental. São Paulo: Atlas, 2009. 310p. 
TACHIZAWA, T. Gestão ambiental e responsabilidade social corporativa. 3 ed. São Paulo: Atlas, 2005. 427p.

TINOCO, J. E. P.; KRAEMER, M. E. P. Contabilidade e gestão ambiental. 3 ed. São Paulo: Atlas, 2011. 278p.

\section{APÊNDICE A}

Questionário

A) Aspectos do Cargo

1) Qual secretaria da prefeitura que o Sr. (a) trabalha?

2) Qual função desempenha?

B) Aspectos gerais sobre meio ambiente

3) As questões ambientais, como poluição, desmatamentos, etc. afetam o seu dia-a-dia?

( ) Sim, um pouco.

( ) Sim, bastante.

( ) Não afetam.

4) Afetando ou não o seu dia-a-dia, as questões ambientais (como poluição, desmatamento etc) fazem parte de suas preocupações?

( ) Sim, é uma das maiores preocupações.

( ) Sim, mas é uma preocupação secundária, de menor importância.

( ) Não faz parte de minhas preocupações.

5) O Sr. (a) sabe o que são práticas de gestão ambiental?

( ) $\operatorname{Sim}$

( ) Não

$\Rightarrow$ Se sim, o Sr. (a) realiza alguma prática de gestão ambiental na sua casa?

( ) $\operatorname{Sim}$

( ) Não

máximo 3 opções):

-Em caso afirmativo, quais destas práticas são as que mais realiza? (Favor marcar no

( ) Economia de energia

( ) Economia de água

( ) Consumo produtos orgânicos e ecologicamente sustentáveis

( ) Faço coleta seletiva dos resíduos

( ) Evito compra de produtos que possuem excesso de embalagem

( ) Possuo automóvel próprio, mas procuro utilizar transporte coletivo

( ) Outros :: Favor informar:

C) Meio ambiente e trabalho

6) Existe alguma prática de gestão ambiental ou algum programa relacionado a meio ambiente na prefeitura?

( ) $\operatorname{Sim}$

( ) Não

$\Rightarrow$ Se sim, favor informar qual prática existe. 
$\Rightarrow$ Se não, porque ainda não foi feito nenhum programa ambiental?

7) $\mathrm{O} \mathrm{Sr}(\mathrm{a})$ sabe como funciona a coleta seletiva?

( ) $\operatorname{Sim}$

( ) Não

8) Existe programa de coleta seletiva em seu setor de trabalho?

( ) Sim

( ) Não existe.

( ) Não estou informado.

$\Rightarrow$ Caso exista coleta seletiva, O Sr. (a) joga o lixo e demais resíduos lixeira da coleta seletiva?

( ) $\mathrm{Sim}$

( ) Não

( ) Às vezes

- Caso tenha respondido na pergunta anterior, NÃO ou ÀS VEZES, quais seriam as maiores dificuldades?

( ) preguiça

( ) esquecimento

( ) não sei separar o lixo ou resíduo conforme o que é exigido na coleta seletiva.

( ) Outros :: Favor informar:

$\Rightarrow$ Caso exista coleta seletiva, quais as práticas relacionadas ao programa de coleta seletiva que o Sr. (a) pratica?
( ) separo o papel branco de demais tipos de papéis.
( ) jogo latinhas na lixeira de alumínio.
( ) jogo o plástico na lixeira dos plásticos.
( ) Outros :: Favor informar:

9) Quais as práticas o Sr. (a) executa para contribuir na economia e na preservação do meio ambiente na Prefeitura?

( ) evito desperdícios de energia elétrica, procurando sempre desligar aparelhos, interruptores etc.

( ) sempre verifico que alguma torneira está vazando e me preocupo com desperdício de água.

( ) procuro separar os resíduos em lixeiras específicas, procurando contribuir na coleta seletiva.

( ) Não faço nenhuma prática ligada ao meio ambiente. a respeito.

( ) Ainda não faço nada relacionado ao meio ambiente mas gostaria de fazer alguma coisa

( ) Outros :: Favor informar:

10) O Sr. (a) tem conhecimento de alguma Lei relacionada à responsabilidade dos órgãos públicos com relação à separação dos resíduos descartados?

( ) Desconheço se existe tal Lei.

( ) Existe Lei a respeito e aqui a cumprimos.

( ) Existe Lei, mas estamos nos adequando para cumpri-la.

( ) Com certeza não existe tal Lei.

11) A Lei $n^{\circ} 9.795$ de 27 de abril de 1997 e o Decreto $n^{\circ} 5.940$ de 25 de outubro de 2006 instituem a separação dos resíduos recicláveis descartados pelos órgãos e entidades da Administração Pública Federal direta e indireta, na fonte geradora. Embora seja uma lei federal, ela deveria se aplicar também aos órgãos municipais, como é o caso da Prefeitura?

( ) Sim 


\section{( ) Não}

12) Quais as maiores vantagens da existência de uma lei municipal que instituísse a separação e reciclagem de materiais? (ASSINALE 5 PARA A MAIOR VANTAGEM ATÉ 1 PARA A MENOR VANTAGEM).

( ) aumento da conscientização das servidores municipais.

( ) exemplo que a prefeitura daria a outros órgãos públicos e também a empresas.

( ) respeito ao meio ambiente.

( ) possibilidade de reutilização de materiais ou mesmo venda.

( ) Outros :: Favor informar:

13) No geral, a prefeitura tem demonstrado interesse em relação às questões ambientais? Sim ou não e por que?

14) O Sr. (a) teria alguma sugestão relacionada a melhoria em termos ambientais na Prefeitura de São Gabriel? 